\title{
From the ground up
}

\section{Lessons learned from a librarian's experience with digitizing special collections}

\author{
by Beth M. Russell
}

D igitizing library collections is becoming a common request, and libraries are responding to these requests by attempting to make images of rare or interesting materials available to a wider, "virtual" audience.

My involvement in digitization began quite by accident; the chance to work on a largescale digitization project crossed my desk completely unsolicited. As a special collections cataloger with just enough computer expertise to know that imaging was a complicated and demanding process, my first reaction was far from enthusiastic.

Nonetheless, more than two years after beginning the project, I can now point to a large database of searchable photographs that has already proven useful to researchers. ${ }^{1} \mathrm{My}$ experiences are living proof that starting a digitization project from the ground up can be done.

This article will highlight how the digitization project was built from the ground up, stressing a few simple lessons learned that may prove useful for other librarians who find themselves in a similar situation. In short,
I would advise librarians beginning such a project from scratch to keep in mind three simple maxims: 1) do your research, 2) nurture collaborations, and 3) be flexible.

\section{Beginnings}

A digitization initiative was in the works at Texas A\&M University long before my arrival in 1996. I was unaware of this, though, when I was encouraged to pursue grant funding from TexShare to make ac-

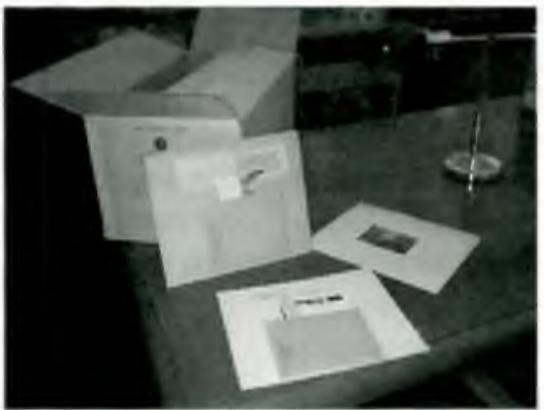

The original boxes and housings of the material and the state in which it arrived at the archives, after many years of storage. cessible a collection of thousands of agricultural photographs. The program, called a TexShare Access to Local Holdings grant at the time, and now named TexTreasures, was designed to assist libraries "to provide access to their special or unique local collection holdings and to make information about these holdings available to library users across the state."

This was clearly a case of having the right knowledge at the right time. I had been working with a collection of photographs from the university's Agricultural Communications Office for a short time, using several images to illustrate a library publication and research-

\section{About the author}


the first student worker. Instead of digitizing, she was put to work sleeving and foldering photographs, assigning unique item numbers to each based on the box number in which the photographs had arrived at the archives. Initially, I thought this would get work underway for a few months, and that this preservation processing would eventually be carried out concurrently with the digitization.

To say that Grewal faced innumerable challenges in procuring hardware and software would be an understatement, and I am sure it comes as no surprise to anyone who has attempted to start up a similar facility. I will simply advise anyone planning on purchasing and setting up a state-of-the-art imaging center to remain flexible and plan ahead.

Faced with a deadline and no usable computers, I got creative. Preservation processing continued while a temporary Microsoft Access database was set up (with the help of the staff of the nascent Digital Library) for entry of descriptive records. The database was designed to allow input of all the information fields that appeared in the photographic files. The cardstock that the photographs were mounted often listed a negative number, photographer, county,

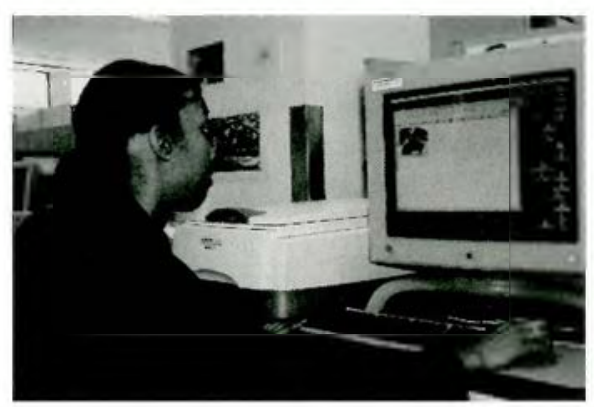

A student worker in the Digital Library manipulates an image from the Texas Agricultural Extension Service collection. date, or caption. Since some photographs did not have captions, or had captions that did not accurately describe the contents of the image, an additional field for a descriptive caption was added.

In retrospect, the design of the database was remarkably workable; although we encountered several problems that did not fit the "ideal" model, we were able to modify the data to record all the necessary information.

\section{The database}

Creating the database quickly revealed itself to be the most time-consuming part of the process. Of course, there was the limitation of typing speed, even though we had designed the data entry form to be easily navigable with minimal reliance on mousing. Students unfamiliar with the vocabulary of agriculture (or more specifically, the agriculture of mid-century America) composed some interesting descriptions of machinery, plants, and animals.

In fact, training and supervising the summary writing was a major concern because everyone had a different idea of how much information was enough and how to best compose that information. In fact, we were limited to a certain field length because of the setup of the database. This was only a problem a few times because some photos had pages and pages of typed "captions." For the most part, this limit forced the students to think of succinct ways to represent an image's content in text and will hopefully be helpful to users.

My goal, after I had scheduled four students for the project, was to have one student working on data entry from 8 a.m. to 5 p.m., Monday through Friday (office hours of the Digital Library). Additional students worked on preserving the material, then the actual scanning, and finally, problem solving and cleanup.

\section{The scanning phase}

A number of unrelated factors kept the Texas A\&M Digital Library from having its arsenal of scanning equipment up and running on the initial timetable. Instead, three MacIntosh G3s were used, running first the software resident on the flatbed scanners and then on Adobe Photoshop, often all three at the same time.

Where negatives were present, these were scanned; otherwise the actual prints were scanned, cropped, and just barely cleaned up. Because we could not create digital watermarks, we decided to mount monitor-level images and urge people to contact the Cushing Library to obtain high-quality (digital or print) copies. Therefore, very little image enhancement was done.

Despite these issues, the scanning phase was completed well ahead of schedule, and students began working on other projects while the database was being completed. Cleanup began, but it was complicated by 
system differences between the (PC-based) database and the (Apple-based) stored images. All images were backed up on ZIP disks, and the unique numbers (which had been used as filenames) were sorted and eyeballed for any obvious errors.

Later, two students working together would call up a database record, check it for mistakes or for problems with the description, then consult the accompanying image; many problems were discovered this way. Some images had been very poorly scanned or over- or under-adjusted. Often there was a database record for an item but no scan or vice versa. These problems had to be resolved by pulling the files in question (which had been returned to their permanent home in the Cushing Library, a few buildings away), often re-scanning and rekeying data.

\section{The Web phase}

During cleanup, I began working with Digital Library staff to plan the Web interface for the database. Again, this was a trial-and-error process. While I had designed basic personal Web pages for years, I had no idea how to design a graphics-intensive site that would link to a database mounted on a server. I sometimes resorted to sketching out on paper how I wanted results displays to look.

There was a high learning curve for the students, the Digital Library staff, and myself in the project. I would advise other librarians who anticipate a similar project to hire students familiar with digitization and photographic manipulation, if possible. The graduate assistant working for the Digital
Library also had to learn database and Web site design from scratch, so there was sometimes difficulty in knowing just what we could do. Still, given the time constraints of the process, I was very fortunate to have worked with an enthusiastic and competent group of people. I certainly enjoyed the learning process, however, and the student assistants who went on to work on other projects with the Digital Library clearly learned their lesson.

\section{Conclusion}

If I can do this, anyone can. Certainly having a grant to hire students and a graduate assistant was a major factor in the success of this project, as well having access to the knowledge of others. However, I believe it was a firm understanding of the collection and the ability to think things through that really made this project work.

Regardless of the environment, it's likely that there is someone knowledgeable around to help. As the project manager for this grant, I relied heavily on others for technical expertise and troubleshooting. I would encourage anyone attempting such a project not to reinvent the wheel. Chances are good that there is someone around to help you.

I am very grateful to TexShare for their financial assistance, as well as to Dilawar Grewal and the staff of the Texas A\&M University Digital Library for technical assistance throughout the project.

\section{Note}

1. The database can be accessed at http://dl.tamu.edu/aggiana/collections/ texshare/home.html.

Now you can tell them... those Europe after the wall-professors, business teachers and importers-to-be - not to mention all the Kaliningrad fans - that you've got what they need once a week:

\section{Baltic Basin News}

The newsletter Baltic Basin News has been available for almost 10 years - to those who read Swedish: the Chancellery of the Swedish Prime Minister, construction firms, ambassadors, college teachers, to mention a few. Join them at WWW.probalt.com

Probalt AB, N Bulltoftavägen 65 B, S-212 43 MALMO, Sweden baltseainfo@probalt.se 


\section{EBSCO can help you find the solution.}

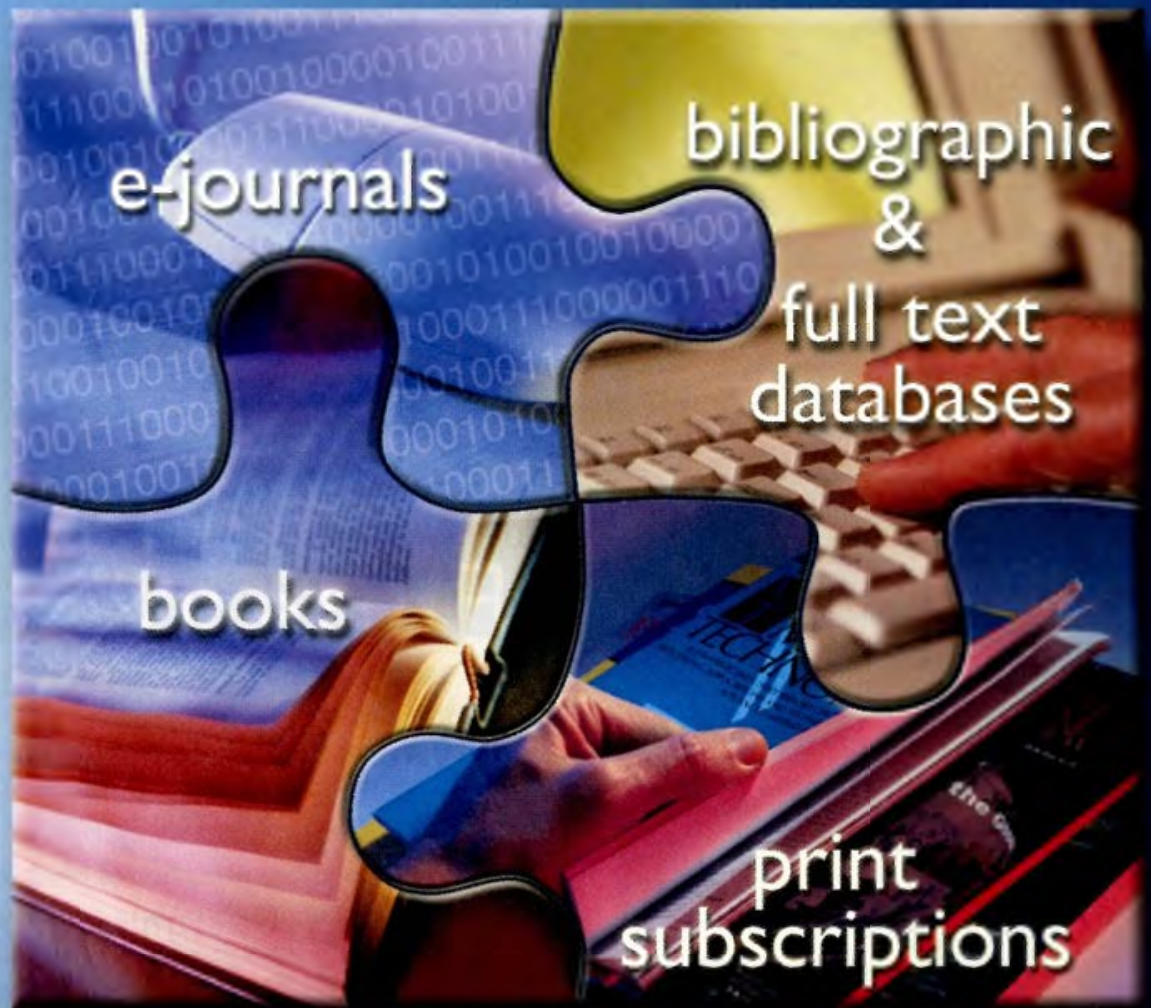

\section{for bringing together the pieces of your information collection.}

For more than 50 years EBSCO has provided subscription management services to libraries and organizations of all types. Today, we offer solutions for many of your library's information resources - e-journals, databases, print subscriptions and books - backed by the same superior service for which we have always been known.
For more information, visit us online at www.ebsco.com

Our integrated online research services give users easy access to full text in databases and electronic journals. EBSCO Book Services allows administrators to manage individual book purchases from their desktops. And virtually all aspects of serial subscriptions can be managed efficiently through our EBSCONET Serials Management System. All services are offered through and supported by EBSCO's Regional Office network, covering 21 countries and six continents.

EBSCO Information Services ... bringing together the pieces of your information collection.

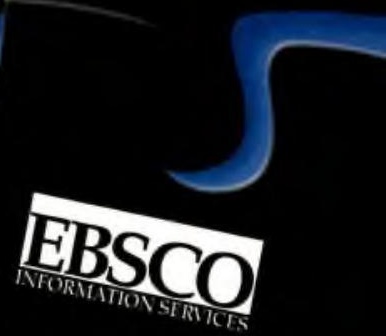


-

$\bullet$

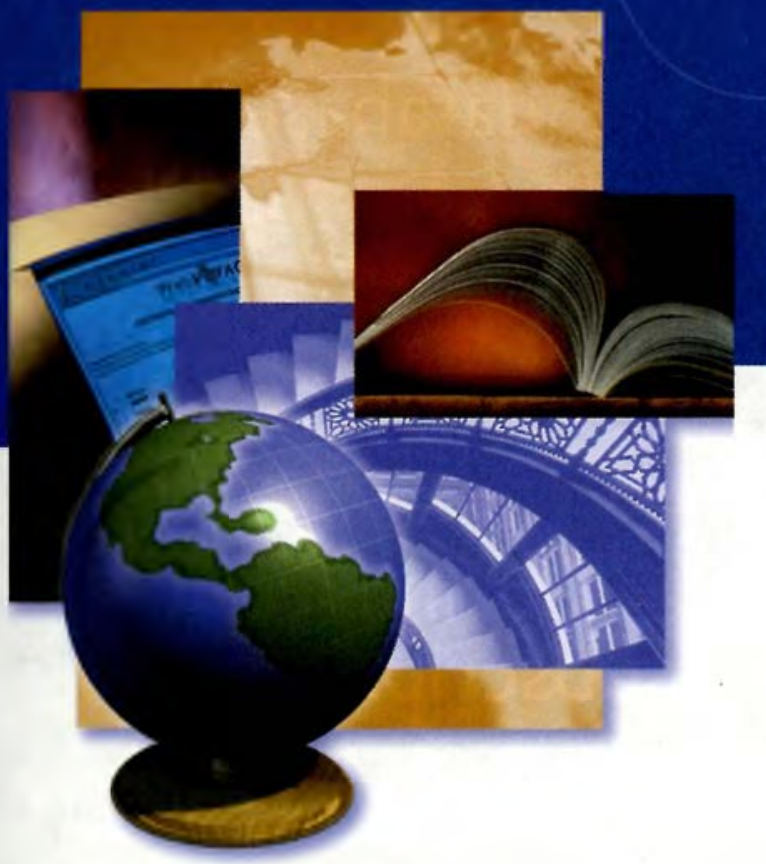

Endeavor

Information Systems

\author{
Smart \\ Design \\ - \\ Solid \\ Decision.
}

Libraries rely on Voyager for clear, quick, progressive technologies to advance workflows and reveal relevant resources. Only ENCompass takes libraries to the next level in organizing, searching and linking print and virtual collections. Now LinkFinderPlus connects researchers with even more resources from CrossRef and beyond. Endeavor creates the tools to integrate materials; libraries and researchers discover the rewards.

Visit us at ALA booth \#2047

\title{
Endeavor
}

Smart Design. Solid Decision.

Endeavor Information Systems Inc. - 2200 E. Devon, Suile 382 - Des Plaines, II 60018-4505 - 1-800-762-6300 - umw.endinfosys.com 